\title{
Role of EGFR and HER-2/NEU Expression in Gall Bladder Carcinoma (GBC)
}

\author{
Chhanda Das ${ }^{1}$ Madhumita Mukhopadhyay ${ }^{1}$ Srijana Subba ${ }^{1}$ Ashis Kumar Saha ${ }^{2}$ \\ Biswanath Mukhopadhyay ${ }^{3}$
}

1Department of Pathology, IPGME\&R, Kolkata, India

${ }^{2}$ Department of Surgery, CNMC\&H, Kolkata, India

${ }^{3}$ Department of Pediatric Surgery, Apollo Gleneagles Hospital, Kolkata, India

J Lab Physicians 2021;13:29-35.

\begin{abstract}
Address for correspondence Chhanda Das, MBBS, DCH, MD (Pathology), DNB (Pathology), DipRCPath (Histopathology), 31 Eastern Park, First Road, Santoshpur, Kolkata 700075, India (e-mail: chhhdas@gmail.com).
\end{abstract}

\begin{abstract}
Keywords

- intestinal adenocarcinoma

- immunohistochemistry

- prognosis
\end{abstract}

Background Gall bladder carcinoma (GBC) is the most common malignancy of the biliary tract. Being known for its geographical and racial variations, and compared with the global statistics, its incidence is higher in the Indian subcontinent, mainly in the northern and eastern regions, accounting for 80 to $95 \%$ of cases.

Aims and Objectives This study was conducted to evaluate the clinic-pathological spectrum and expression of EGFR and HER-2/NEU in GBCs and to understand their relation to prognosis, paving the way for targeted therapies for better treatment outcomes and patient survival.

Materials and Methods This is a prospective study performed in a tertiary care hospital in 30 resected specimens of GBC cases recorded in our Department of Pathology from November 2017 to November 2019. Clinical history including the radiological reports and demographic parameters were included in the study pro forma. Immunohistochemical (IHC) staining for EGFR and HER-2/NEU was performed on all the selected cases. Clinicopathologic parameters like age, sex, histologic type, perineural, and lymphovascular invasion were compared and correlated with EGFR and HER-2/NEU status.

Results Expression of EGFR was found in $93.33 \%$ of cases, which showed a highly significant correlation with histological tumor type $(p=0.000)$. HER-2/NEU expression was found in $56.66 \%$ of cases, which also showed a significant correlation with histological tumour type $(p=0.021)$. We found most of the cases with strong EGFR immunoreactivity $\left(3^{+}\right)$were poorly differentiated tumors and most of the cases showing weak immunoreactivity for EGFR $\left(1^{+}\right)$were well-differentiated. Conversely, in case of HER-2/NEU immunoreactivity, strong staining $(3+)$ was seen in well-differentiated tumors and weak staining $(1+)$ in poorly differentiated tumors. A significant correlation was also found between EGFR and HER-2/NEU expression $(p=0.000)$ and between cholelithiasis and EGFR expression ( $p=0.033)$.

Conclusion EGFR is expressed in most cases of GBC. Its expression is more in poorly differentiated carcinomas as compared to the well-differentiated carcinomas, whereas HER-2/NEU expression is more in well-differentiated carcinomas. Therefore, they may serve as independent prognostic factors and also as targets for molecular therapy in GBCs. published online May 19, 2021
DOI https://doi.org/ $10.1055 / \mathrm{s}-0041-1726563$ ISSN 0974-2727.
(02021. The Indian Association of Laboratory Physicians.

This is an open access article published by Thieme under the terms of the Creative Commons Attribution-NonDerivative-NonCommercial-License, permitting copying and reproduction so long as the original work is given appropriate credit. Contents may not be used for commercial purposes, or adapted, remixed, transformed or built upon. (https://creativecommons.org/licenses/by-nc-nd/4.0/).

Thieme Medical and Scientific Publishers Pvt. Ltd. A-12, 2nd Floor, Sector 2, Noida-201301 UP, India 


\section{Introduction}

Gall bladder cancer (GBC) is the most common cancer of the biliary tract and ranks sixth among the gastrointestinal (GI) cancers. ${ }^{1}$ It displays wide geographical and ethnical variations, with highest incidence being reported in the Mapuche people of Chile, followed by India, Eastern Asia and some Eastern and Central European countries. ${ }^{2}$ It is associated with poor prognosis and low survival, attributed to the disease being in an advanced stage at presentation. ${ }^{1,3}$ In advanced diseases, the median overall survival is less than 12 months even with palliative treatment. ${ }^{4}$ In Chile and India, GBC occurs predominantly in females with gallstones, whereas in Eastern Asia, it is also equally common in men, and the association with gallstone being much weaker. Aflatoxin $\mathrm{B} 1$, which is found in the improperly stored foods in rural areas, has also been implicated to play a role in triggering the inflammation. Pancreaticobiliary maljunction (PBM) (union of the common bile duct with the main pancreatic duct above the sphincter of Oddi) is yet another established risk factor. Increased expression of EGFR and HER-2/NEU has been noted in GBCs.

Several studies have been performed around the globe, examining the expression of these markers by these carcinomas. $^{5-7}$ EGFR is a protein kinase receptor which is involved in signal transduction, affecting various cellular activities such as metabolism, transcription, cell cycle progression, apoptosis and differentiation. Overexpression of receptors, gene amplification, and the loss of inhibitory signals are among the various mechanisms of increased EGFR activation, which results in phosphorylation of intracellular substrates downstream, leading to subsequent activation of mitotic pathways. ${ }^{8}$ HER-2/NEU, a protein mostly present at the surface epithelium of large and septal bile ducts, is encoded by ERBB2 gene in humans. Overexpression of this gene product, which occurs in about one-fourth to two-thirds of the biliary tract carcinomas, may be used as a phenotypic marker for neoplastic transformation with a poor prognosis. ${ }^{9}$

In the present study, we assessed the expression of EGFR and HER-2/NEU in GBC, correlated the findings with the clinical parameters and histological tumor types, and evaluated the role of EGFR and HER-2/NEU as a prognostic marker and a likely indicator for targeted therapy of GBC.

\section{Materials and Methods}

It was a cross-sectional observational study performed in the Department of Pathology in collaboration with the Department of Surgery after obtaining the approval from the Institutional Ethical Committee. A total of 30 resected specimens of patients with GBC were selected over a study period of 24 months from November 2017 to November 2019. After processing the tissues, as per the standard procedure, hematoxylin and eosin stained sections were subjected to histopathological evaluation. Following the confirmation of GBC, histological grades and tumor subtypes were assigned (-Figs. 1-4). Immunohistochemistry (IHC) was performed for EGFR and

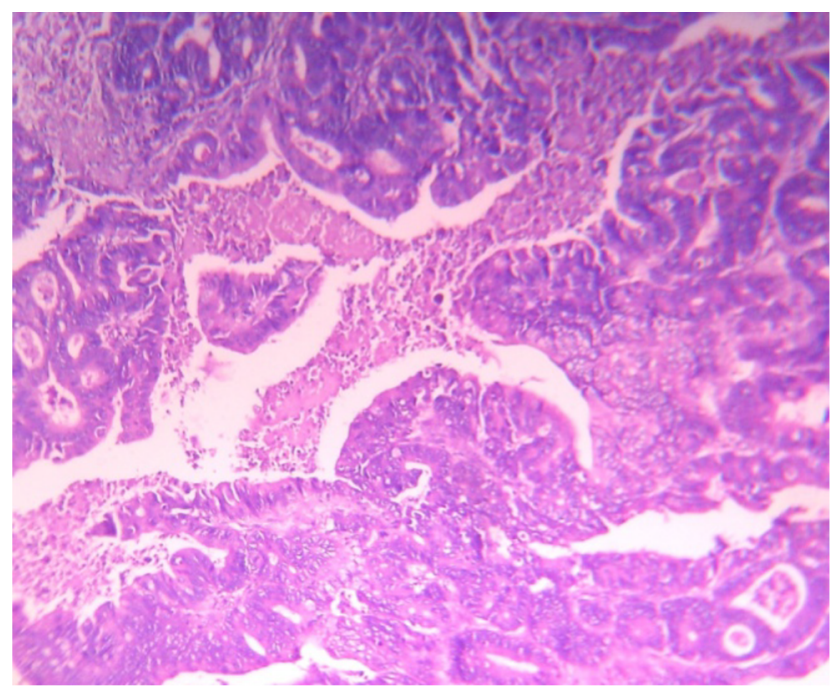

Fig. 1 Photomicrograph showing intestinal variety of adenocarcinoma $(\times 400)$ hematoxylin and eosin $(H \& E)$.

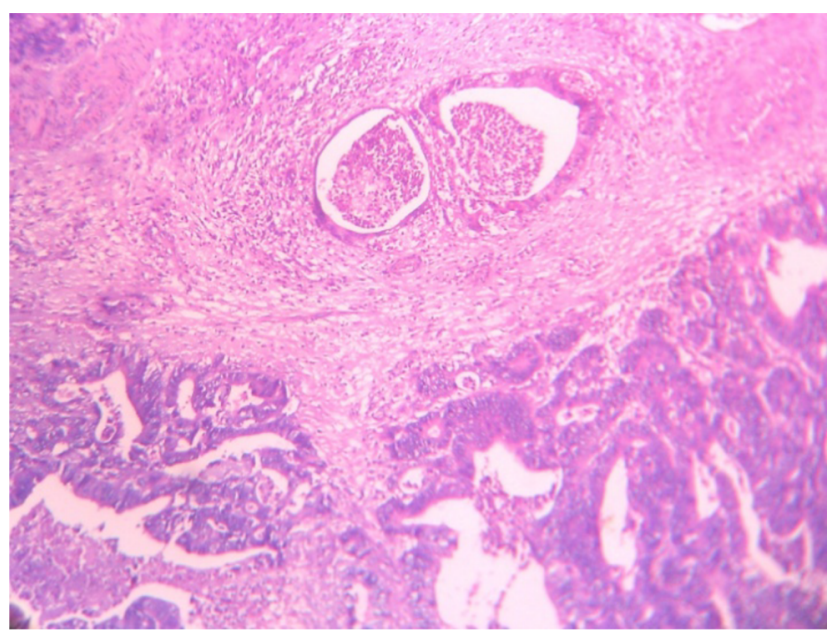

Fig. 2 Photomicrograph showing intestinal variety of adenocarcinoma $(\times 400)$ hematoxylin and eosin $(\mathrm{H} \& \mathrm{E})$.

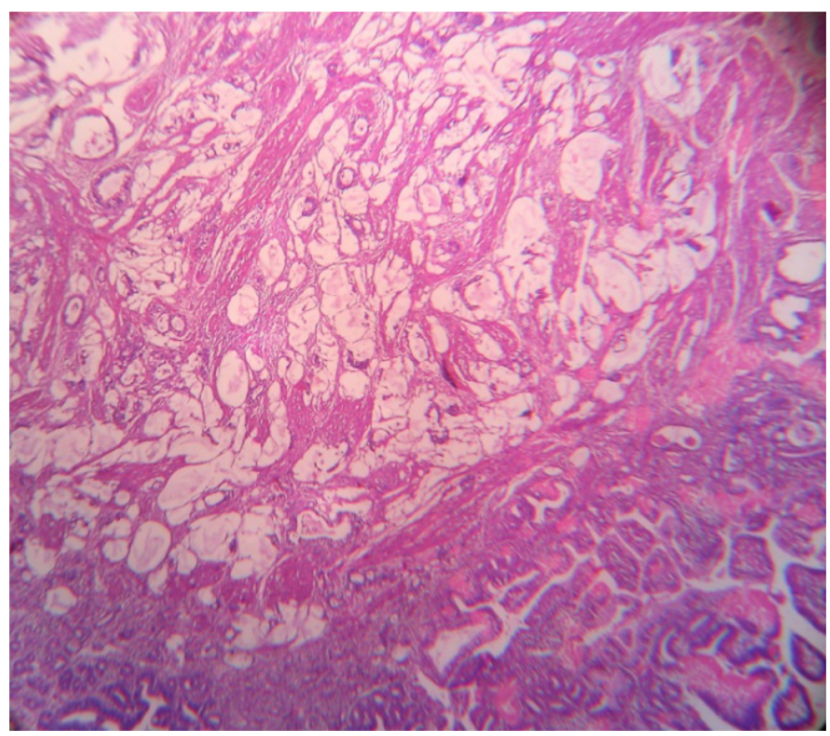

Fig. 3 Photomicrograph showing mucinous variety of adenocarcinoma $(\times 100)$ hematoxylin and eosin $(\mathrm{H} \& \mathrm{E})$. 


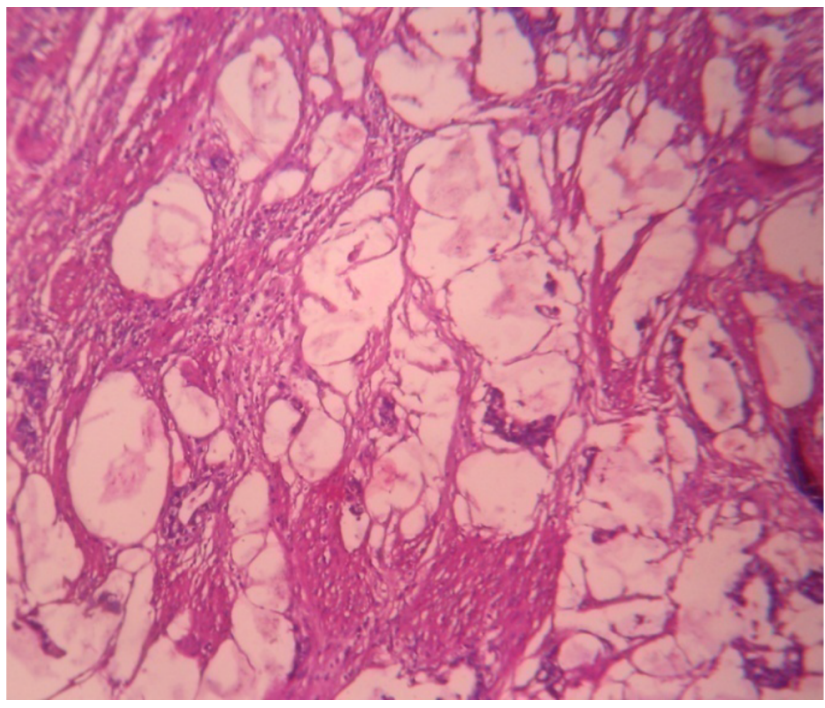

Fig. 4 Photomicrograph showing mucinous variety of adenocarcinoma $(\times 400)$ hematoxylin and eosin (H\&E).

HER-2/NEU in all cases. Four microns-thick sections were prepared from the formalin-fixed and paraffin-embedded tissue samples. Subsequently, they were stained with antibody against EGFR mouse monoclonal antibody Dako Clone: H 11 Lot no. AN7810616B, dilution: 1:100 for positive control of EGFR, normal endometrial tissue was utilized, and negative control was achieved by the omission of primary antibody in EGFR. Similarly, prepared sections were stained with antibody against HER-2 (polyclonal rabbit anti-human antibody directed against c-erbB-2 oncoprotein, Dako: Lot no. 20067288). For positive control of HER-2, breast carcinoma tissue was chosen, and negative control was achieved by the omission of primary antibody in HER-2.

\section{Interpretation of Immunostaining}

The interpretation of staining of EGFR and HER-2/NEU was reported as percentage of positive cells and intensity of staining. Cell membrane staining was used to assess positivity for EGFR and HER-2/NEU. EGFR intensity was scored from 0 to $3+$ and the threshold for positivity was +1 staining intensity in $10 \%$ of tumor cells. (-Figs. 5-10).

The quantification of EGFR immunostaining was determined as shown in - Table 1 . $^{10}$

The staining pattern for HER-2 was determined as shown in - Table $\mathbf{2}^{11}$

\section{Statistical Analysis}

All data were thoroughly tabulated on Microsoft Excel worksheet. Mean values with standard deviation were calculated for quantitative variables, whereas proportions represented qualitative variables. The Chi-square test was conducted to assess the correlation between the clinicopathological parameters and the IHC results. Statistical analyses were performed using SPSS software version 20.0 (IBM Inc.). Two-tailed $p<0.05$ was considered as statistically significant.

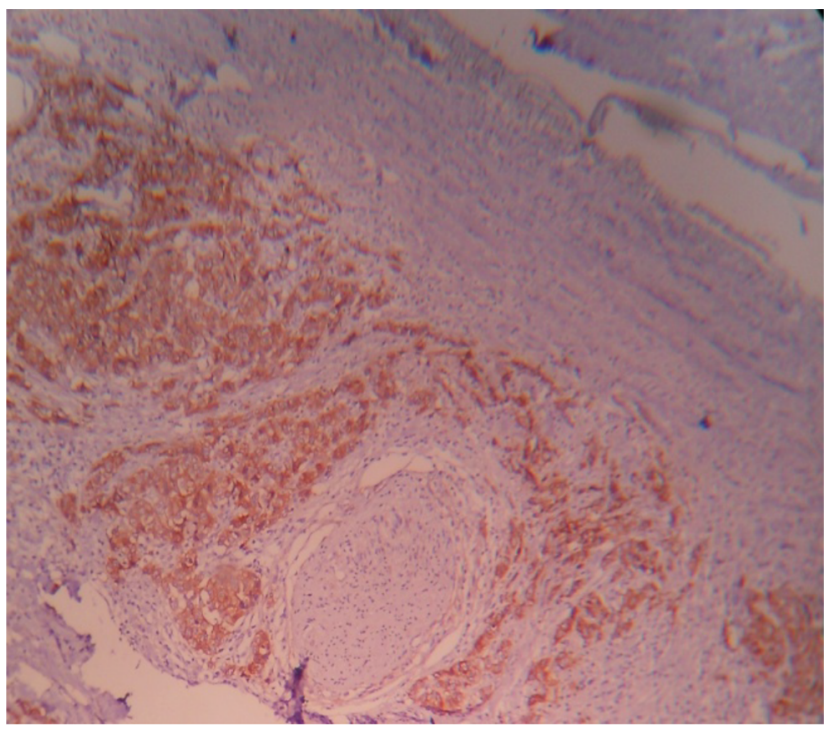

Fig. 5 Photomicrograph showing strong membranous staining pattern of EGFR in poorly differentiated carcinoma $(\times 100)$.

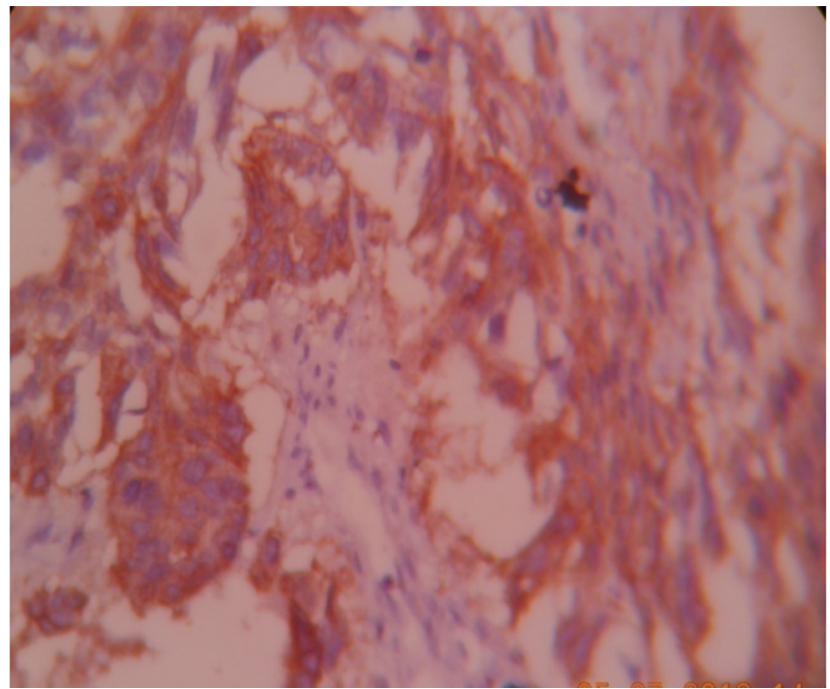

Fig. 6 Photomicrograph showing strong membranous staining pattern of EGFR in poorly differentiated carcinoma $(\times 400)$.

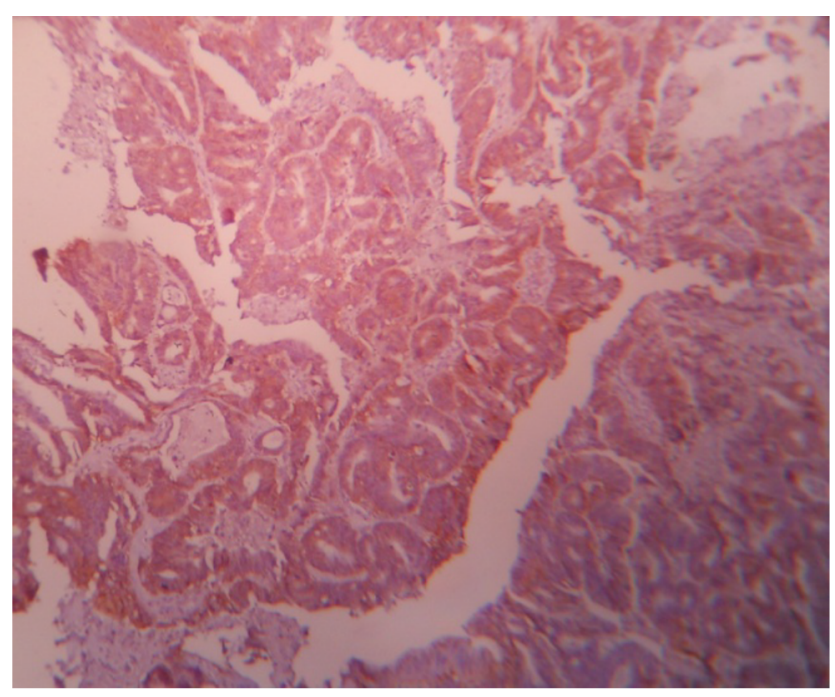

Fig. 7 Photomicrograph showing strong membranous staining pattern of HER-2/NEU in well-differentiated carcinoma $(\times 100)$. 


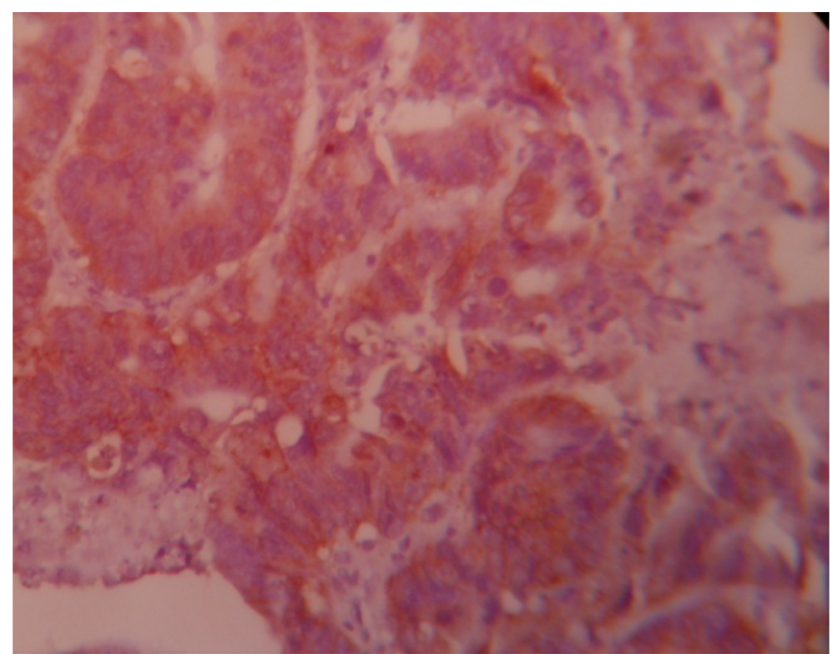

Fig. 8 Photomicrograph showing strong membranous staining pattern of HER-2/NEU in well-differentiated carcinoma $(\times 400)$.

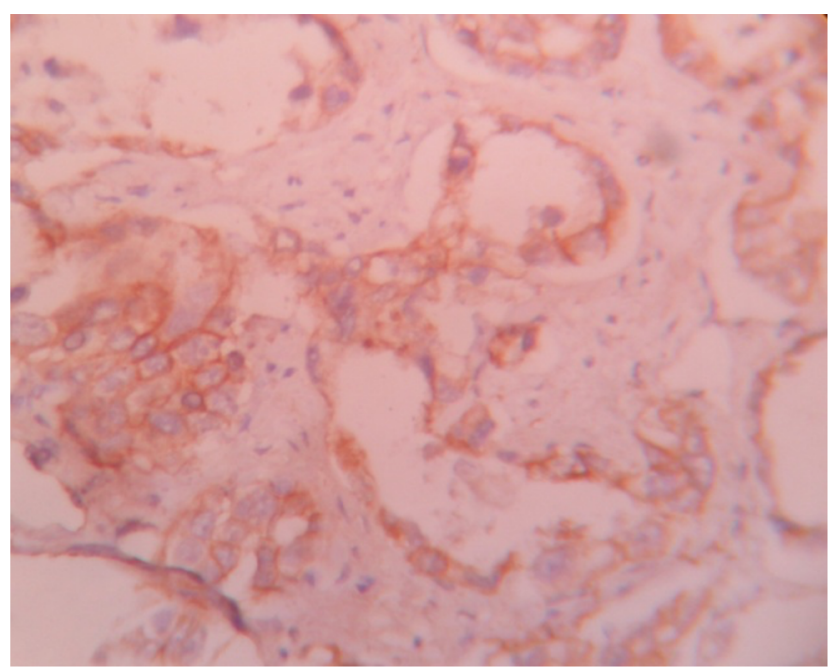

Fig. 9 Photomicrograph showing EGFR moderate staining in mucinous carcinoma of gall bladder $(\times 400)$.

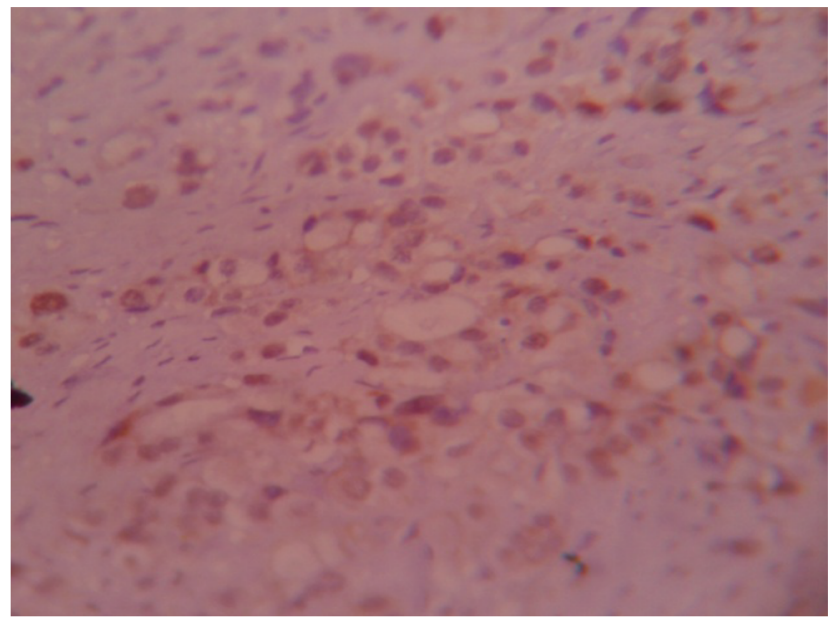

Fig. 10 Photomicrograph showing HER-2/NEU mild staining in poorly differentiated carcinoma of gall bladder $(\times 400)$.
Table 1 Quantification of EGFR immunostaining

\begin{tabular}{|l|l|l|}
\hline EGFR score & Positive cells & Staining intensity \\
\hline 0 & $<10 \%$ & Faint/none \\
\hline $1+$ & $>10 \%$ & Weak \\
\hline $2+$ & $\geq 10 \%$ & Moderate \\
\hline $3+$ & $\geq 10 \%$ & Strong \\
\hline
\end{tabular}

Table 2 Interpretation of HER-2 immunostaining

\begin{tabular}{|l|l|}
\hline Result & Criteria \\
\hline Score 0 & No staining observed. \\
\hline Score 1+ & $\begin{array}{l}\text { Faint membrane staining in }>10 \% \text { of tumor cells in } \\
\text { part of cell membrane. }\end{array}$ \\
\hline Score 2+ & $\begin{array}{l}\text { Weak to moderate incomplete membrane staining in } \\
\text { over 1\% of tumor cells. }\end{array}$ \\
\hline Score 3+ & $\begin{array}{l}\text { Strong complete membrane staining in over 1\% of } \\
\text { tumor cells. }\end{array}$ \\
\hline
\end{tabular}

\section{Results}

In our series of 30 patients, 21 (70\%) were females and 9 (30\%) were males. Age ranged from 23 to 75 years, with mean age being 52.33 years. Fourteen (46.66\%) presented with pain in the abdomen and 16 (53.33\%) presented with jaundice. On radiological evaluation, 19 (63.33\%) cases showed GB mass, $8(26.66 \%)$ showed intraluminal mass, and 3 (10\%) showed diffuse intramural thickening. Cholelithiasis was associated in 19 (63.33\%) cases. Regarding the histological tumor type, 13 (45.35\%) had intestinal type of adenocarcinoma, 7 (25.33\%) had mucinous carcinoma, 7 (25.33\%) had biliary carcinoma, 2 (6.66\%) had poorly cohesive carcinoma, and 1 (3.33\%) had adenosquamous carcinoma. Lymphovascular invasion was seen in $11(36.66 \%)$ and perineural invasion in 18 (60\%) patients.

With regard to the hormone receptor status, EGFR was positive in 28 (93.33\%) of patients, out of which 5 (17.85\%) were assigned with score 1,14 (50\%) with score 2, and 9 (32.15\%) with score 3. HER-2/NEU was found to be positive in 17(56.66\%) patients, out of which 9 (52.94\%) were assigned with score 1 , 6 (35.29\%) with score 2, and 2 (11.77\%) with a score of 3 . The correlations between EGFR expression and clinicopathologic parameters are summarized in - Table 3. No significant correlation found between age group and EGFR expression, but a statistically significant correlation was found between histological tumor type $(p=0.000)$ and EGFR expression as well as between cholelithiasis $(p=0.033)$ and EGFR expression.

The correlations between HER-2/NEU expression and clinicopathological parameters are summarized in - Table 4. No significant correlation was found between HER-2 expression and age group and between HER-2/NEU and sex. Cholelithiasis and HER-2 expression also showed no significant correlation. However, there was a statistically significant correlation between HER-2 expression and histological tumor type $(p=0.02)$. There was a statistically significant $(p=0.000)$ correlation between EGFR and HER-2/NEU expression too (-Table 5 ). 
Table 3 Correlation between EGFR expression and clinicopathological parameters

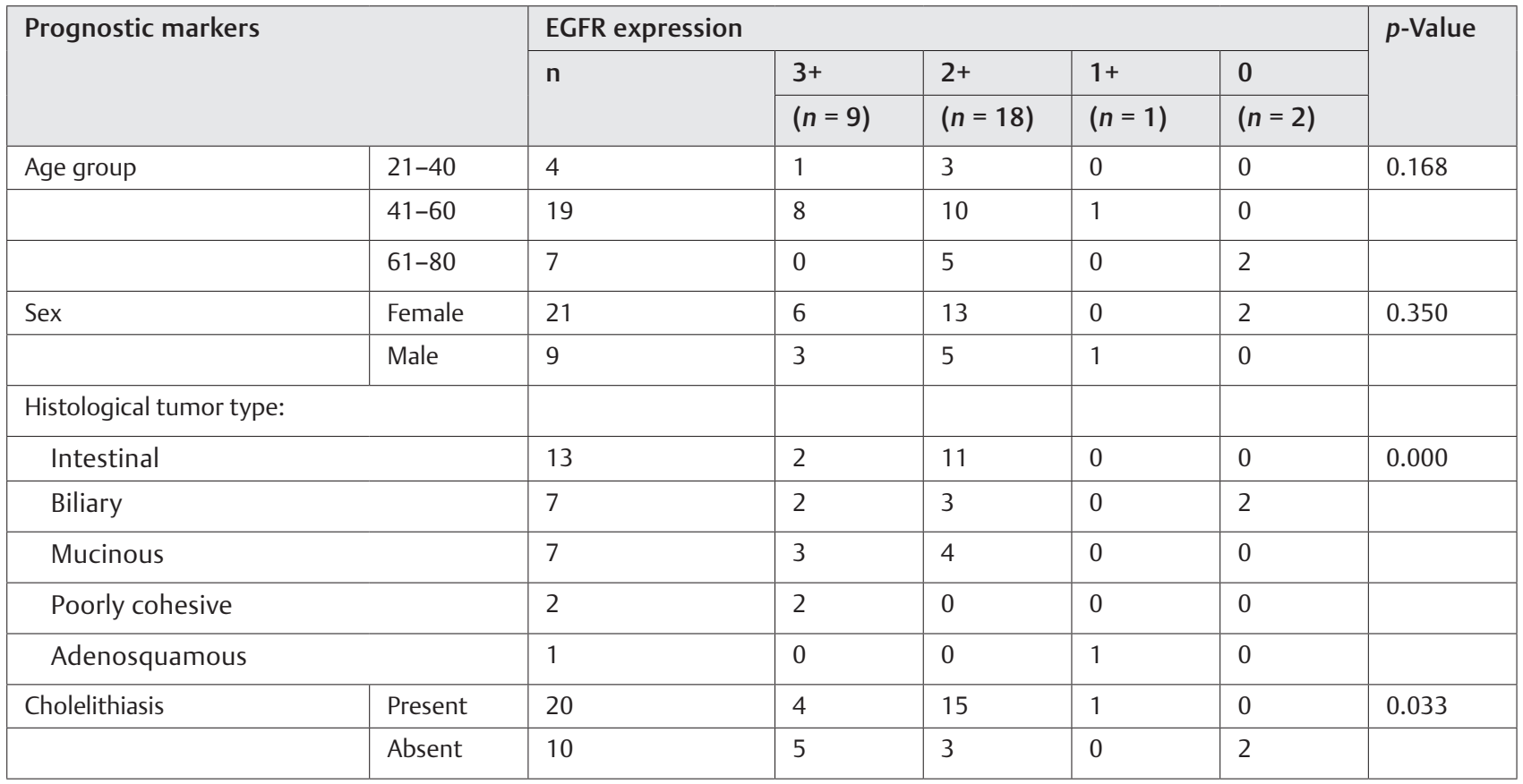

Table 4 Correlation between HER-2/NEU expression and clinicopathological parameters

\begin{tabular}{|c|c|c|c|c|c|c|c|}
\hline \multicolumn{2}{|c|}{ Prognostic parameters } & \multicolumn{4}{|c|}{ HER-2/NEU expression } & \multirow{4}{*}{$\begin{array}{l}0 \\
(n=8) \\
1\end{array}$} & \multirow{4}{*}{$\begin{array}{l}p \text {-Value } \\
0.428\end{array}$} \\
\hline & & \multirow{3}{*}{$\begin{array}{l}n \\
4\end{array}$} & \multirow{3}{*}{$\begin{array}{l}3+ \\
(n=3) \\
1\end{array}$} & \multirow{3}{*}{$\begin{array}{l}2+ \\
(n=9) \\
1\end{array}$} & \multirow{3}{*}{$\begin{array}{l}1+ \\
(n=10) \\
1\end{array}$} & & \\
\hline & & & & & & & \\
\hline Age group & $21-40$ & & & & & & \\
\hline & $41-60$ & 19 & 0 & 7 & 5 & 7 & \\
\hline & $61-80$ & 7 & 2 & 1 & 4 & 0 & \\
\hline Sex & Female & 21 & 3 & 5 & 4 & 9 & 0.674 \\
\hline & Male & 9 & 0 & 3 & 2 & 4 & \\
\hline Histological th & & & & & & & \\
\hline Intestinal & & 13 & 1 & 7 & 3 & 2 & 0.021 \\
\hline Biliary & & 7 & 2 & 2 & 1 & 2 & \\
\hline Mucinous & & 7 & 0 & 0 & 6 & 1 & \\
\hline Poorly coh & & 2 & 0 & 0 & 0 & 2 & \\
\hline Adenosqu & & 1 & 0 & 0 & 0 & 1 & \\
\hline Cholelithiasis & Present & 20 & 1 & 8 & 7 & 4 & 0.208 \\
\hline & Absent & 10 & 2 & 1 & 3 & 4 & \\
\hline
\end{tabular}

Table 5 Correlation between EGFR and HER-2/NEU expression

\begin{tabular}{|l|l|l|l|l|l|}
\hline \multirow{2}{*}{ EGFR } & \multicolumn{4}{l|}{ HER-2/NEU expression } & \multirow{2}{*}{$p$-Value } \\
\cline { 2 - 6 } & 0 & $1+$ & $2+$ & $3+$ & $(n=2)$ \\
\cline { 2 - 6 } & $(n=13)$ & $(n=9)$ & $(n=6)$ & 2 & 0.000 \\
\hline $0(n=2)$ & 0 & 0 & 0 & 0 & \\
\hline $1+(n=5)$ & 1 & 0 & 9 & 1 & \\
\hline $2+(n=14)$ & 1 & 7 & 0 & 0 & \\
\hline $3+(n=9)$ & 6 & 3 & & & \\
\hline
\end{tabular}




\section{Discussion}

In our study, the median age of presentation of GBC was 52.3 years. Similar results were observed in other studies. ${ }^{12-14}$ In yet another study conducted by Chijiiwa et al, perineural invasion was found in $43 \%$ of cases and lymphovascular invasion in $68 \%$ of cases. ${ }^{15}$ However, we found perineural invasion in $60 \%$ and lymphovascular invasion in $36.66 \%$ of patients, which was also nearly supportive to the previous studies.

To date, many studies have demonstrated the correlation of biomarkers associated with tumorigenesis and prognosis, which indicates that these markers may have complementary roles in improving the diagnosis and predicting the prognosis of cancers. ${ }^{16}$ The identification of the risk of mortality and disease recurrence in cancer patients is critical for guiding surveillance and selecting adjunctive therapies. It has been reported that EGFR and HER-2/NEU expression are related to clinicopathological parameters in breast cancer and colonic cancer. Through our study, we found that EGFR and HER-2/NEU are not related to age and gender in GBC. As found by Hadi et al in their study, cholelithiasis is closely related to $\mathrm{GBC} .{ }^{17}$ We also found a significant correlation between EGFR expression in GBC and cholelithiasis.

Since the preceding years, the pathogenesis of GBC has become an important and a much concerned phenomenon and often highlights the involvement of major proto-oncogenes such as EGFR and HER-2/NEU. ${ }^{18}$ In the management of GBC, several phase II trials have been performed, investigating the role of tyrosine kinase inhibitors like Erlotinib. ${ }^{19-21}$ Therefore in this study, we have attempted to identify the immune expression of EGFR and HER-2 in 30 patients with GBC, assessing their correlation with the various clinicopathological parameters to understand their role in targeted therapy and significance in prognosis. Several studies from Europe, Asia and Australia have complemented this work by examining the level of expression of EGFR in biliary tumors (- Table 6). These studies demonstrated a consistent and significant overexpression of EGFR in biliary tumors. In a study performed by Lee et al on IHC stains for EGFR on 13 GBC specimens from Australia, $100 \%$ of the GBC specimens were found to stain strongly positive for EGFR. ${ }^{22}$ In this context, in yet another study performed by Kaufman et al in a series of 16 patients, 15 (93.75\%) were noted to overexpress EGFR. In the present study, EGFR expression was found in $93.33 \%$ (28 patients), which is concordant to the previous studies. ${ }^{23}$

In a study conducted by Viswanath et al, they found that advanced biliary tract malignancies show increased expression of EGFR. ${ }^{24}$ Similarly, in the present study, we found that EGFR expression is more in poorly differentiated advanced tumors.

Thus, our study revealed that EGFR is a prognostic marker of aggressiveness in GBC.
Table 6 Comparative studies on EGFR expression in biliary cancer

\begin{tabular}{|c|c|c|}
\hline Study & $n$ & Immunoreactivity \\
\hline Lee et $\mathrm{a}^{22}$ & $\begin{array}{l}\text { Gall bladder-13, } \\
\text { biliary duct-7 }\end{array}$ & $100 \%, 86 \%$ \\
\hline Zhou et $\mathrm{al}^{5}$ & Gall bladder-41 & $71 \%$ \\
\hline Kaufmann et a ${ }^{23}$ & Gall bladder-16 & $93.57 \%$ \\
\hline Shafizadeh $\mathrm{N}$ et al ${ }^{25}$ & Gall bladder & $80 \%$ \\
\hline Present study & Gall bladder & $93.33 \%$ \\
\hline
\end{tabular}

Various studies have shown that HER-2 protein is variably amplified in 16 to $64 \%$ of $\mathrm{GBCs}{ }^{25-27}$ In the present study, HER-2/NEU immunoreactivity was found to be positive in $56.66 \%$ of GBC cases. However, in a study conducted by Javle et al, HER-2/NEU overexpression was found in $8 / 9$ (88.88\%) of patients with GBC which, though of a much higher percentage than our study, still supports our result. ${ }^{28}$ Through their study, they have also concluded that targeted therapy against HER-2/NEU is a promising treatment strategy for GBC patients.

In a study conducted by Yoshida et $\mathrm{al}^{29}$ they found a significant patient population that can derive benefit from anti-HER-2 therapy by designing planned clinical trials based on preliminary IHC reports. HER-2 can be considered as a potential candidate for targeted therapy in GBC, as several drugs are now available that can successfully inhibit HER-2, as in cases of breast and gastric carcinoma. In a study conducted by Kiguchi et al, it was found that Lapatinib (anti-HER-2 agent), when combined with Gemcitabine, had a synergistic antiproliferative effect on a GBC cell line (TGBC1-TKB) in vitro. ${ }^{30}$

Therefore, in this study, we have attempted to identify the immune expression of EGFR and HER-2 in 30 patients with $G B C$, assessing their correlation with the various clinicopathological parameters to understand their role in targeted therapy and significance in prognosis.

\section{Conclusion}

Our study deals with the clinicopathological parameters and expression of RAS pathway molecules like EGFR and HER-2/ NEU in GBC. The present study revealed that these molecules show significant expression in GBC, suggesting that significant interactions take place among the different members of ErbB family during the process of tumorigenesis. We analyzed the correlation of EGFR and HER-2/NEU expression in different histological subtypes of GBC and also with the clinicopathological parameters. We identified a significant subgroup of GBC cases in which targeted therapy may increase the survival of patients. 


\section{Contributor Details}

Chhanda Das did study designing, literature search, data analysis, and conceptual analysis. Madhumita Mukhopadhyay did literature search and designing. Srijana Subba contributed in literature search, data acquisition, and data analysis. Ashis Kumar Saha did clinical studies, designing, and proof correction. Biswanath Mukhopadhyay did literature search and designing.

\section{Funding}

Nil.

\section{Conflicts of Interest}

None declared.

\section{Acknowledgment}

Nil.

\section{References}

1 Hundal R, Shaffer EA. Gallbladder cancer: epidemiology and outcome. Clin Epidemiol 2014;6:99-109

2 International Agency for Research on Cancer. GLOBOCAN v1.0, Cancer Incidence and Mortality Worldwide: IARC CancerBase No. 11. Available at: http://globocan.iarc.fr/old/ summary_table_site-html.asp? selection $=7080 \&$ title $=$ Gallbladder \&sex $=0$ \&type $=0$ \& window $=1$ \&africa $=1$ \&america $=2 \& a-$ sia $=3$ \&europe $=4 \&$ oceania $=5$ \&build $=6 \&$ sort $=0$ \& submitted . Accessed September 16, 2020

3 Wistuba II, Gazdar AF. Gallbladder cancer: lessons from a rare tumour. Nat Rev Cancer 2004;4(9):695-706

4 Valle J, Wasan H, Palmer DH, et al; ABC-02 Trial Investigators. Cisplatin plus gemcitabine versus gemcitabine for biliary tract cancer. N Engl J Med 2010;362(14):1273-1281

5 Zhou YM, Li YM, Cao N, Feng Y, Zeng F. [Significance of expression of epidermal growth factor (EGF) and its receptor (EGFR) in chronic cholecystitis and gallbladder carcinoma]. Chin J Cancer 2003;22(3):262-265

6 Ariyama H, Qin B, Baba E, et al. Gefitinib, a selective EGFR tyrosine kinase inhibitor, induces apoptosis through activation of Bax in human gallbladder adenocarcinoma cells. J Cell Biochem 2006;97(4):724-734

7 Nakazawa K, Dobashi Y, Suzuki S, Fujii H, Takeda Y, Ooi A. Amplification and overexpression of c-erbB-2, epidermal growth factor receptor, and c-met in biliary tract cancers. J Pathol 2005;206(3):356-365

8 Baselga J, Arteaga CL. Critical update and emerging trends in epidermal growth factor receptor targeting in cancer. J Clin Oncol 2005;23(11):2445-2459

9 Chow NH, Huang SM, Chan SH, Mo LR, Hwang MH, Su WC. Significance of c-erbB-2 expression in normal and neoplastic epithelium of biliary tract. Anticancer Res 1995; 15(3):1055-1059

$10 \mathrm{Kim}$ CH, Kim SH, Park SY, Yoo J, Kim SK, Kim HK. Identification of EGFR mutations by immunohistochemistry with egfr mutation-specific antibodies in biopsy and resection specimens from pulmonary adenocarcinoma. Cancer Res Treat 2015;47(4):653-660

11 Wolff AC, Hammond ME, Hicks DG, et al; American Society of Clinical Oncology; College of American Pathologists. Recommendations for human epidermal growth factor receptor 2 testing in breast cancer: American Society of Clinical Oncology/College of American Pathologists clinical practice guideline update. Arch Pathol Lab Med 2014;138(2):241-256
12 Kapoor VK, McMichael AJ. Gallbladder cancer: an 'Indian' disease. Natl Med J India 2003;16(4):209-213

13 Shukla VK, Khandelwal C, Roy SK, Vaidya MP. Primary carcinoma of the gall bladder: a review of a 16-year period at the University Hospital. J Surg Oncol 1985;28(1):32-35

14 Pandey M, Pathak AK, Gautam A, Aryya NC, Shukla VK. Carcinoma of the gallbladder: a retrospective review of 99 cases. Dig Dis Sci 2001;46(6):1145-1151

15 Chijiiwa K, Nakano K, Ueda J, et al. Surgical treatment of patients with T2 gallbladder carcinoma invading the subserosal layer. J Am Coll Surg 2001;192(5):600-607

16 Ahmad M, Attoub S, Singh MN, Martin FL, El-Agnaf OM. Gamma-synuclein and the progression of cancer. FASEB J 2007;21(13):3419-3430

17 Hadi R, Singhal A, Masood S, Awasthi NP. Expression of ErbB1 and Erb-B2 in cholecystectomy specimen done for benign gall bladder disease. World Journal of Surgical Medical and Radiation Oncology 2014;8:44-49

18 Sergeant G, Lerut E, Ectors N, Hendrickx T, Aerts R, Topal B. The prognostic relevance of tumor hypoxia markers in resected carcinoma of the gallbladder. Eur J Surg Oncol 2011;37(1):80-86

19 Lubner SJ, Mahoney MR, Kolesar JL, et al. Report of a multicenter phase II trial testing a combination of biweekly bevacizumab and daily erlotinib in patients with unresectable biliary cancer: a phase II Consortium study. J Clin Oncol 2010;28(21):3491-3497

20 Philip PA, Mahoney MR, Allmer C, et al. Phase II study of erlotinib in patients with advanced biliary cancer. J Clin Oncol 2006;24(19):3069-3074

21 Chiorean EG, Ramasubbaiah R, Yu M, et al. Phase II trial of erlotinib and docetaxel in advanced and refractory hepatocellular and biliary cancers: Hoosier Oncology Group GI06-101. Oncologist 2012;17(1):13

22 Lee CS, Pirdas A. Epidermal growth factor receptor immunoreactivity in gallbladder and extrahepatic biliary tract tumours. Pathol Res Pract 1995;191(11):1087-1091

23 Kaufman M, Mehrotra B, Limaye S, et al. EGFR expression in gallbladder carcinoma in North America. Int J Med Sci 2008;5(5):285-291

24 Viswanath S, Bhardwaj R, Kapoor A. Clinicopathological significance of epidermal growth factor receptor and vascular endothelial growth factor expression in biliary tract malignancies. J NTR Univ Health Sci 2017;6:82-85

25 Shafizadeh N, Grenert JP, Sahai V, Kakar S. Epidermal growth factor receptor and HER-2/neu status by immunohistochemistry and fluorescence in situ hybridization in adenocarcinomas of the biliary tree and gallbladder. Hum Pathol 2010;41(4):485-492

26 Maurya SK, Tewari M, Mishra RR, Shukla HS. Genetic aberrations in gallbladder cancer. Surg Oncol 2012;21(1):37-43

27 Müller BG, De Aretxabala X, González Domingo M. A review of recent data in the treatment of gallbladder cancer: what we know, what we do, and what should be done. Am Soc Clin Oncol Educ Book 2014 (e-pub ahead of print. doi: https://doi. org/10.14694/edbook_am.2014.34.e165

28 Javle M, Churi C, Kang HC, et al. HER2/neu-directed therapy for biliary tract cancer. J Hematol Oncol 2015;8:58

29 Yoshida H, Shimada K, Kosuge T, Hiraoka N. A significant subgroup of resectable gallbladder cancer patients has an HER2 positive status. Virchows Arch 2016;468(4):431-439

30 Kiguchi K, Ruffino L, Kawamoto T, Ajiki T, Digiovanni J. Chemopreventive and therapeutic efficacy of orally active tyrosine kinase inhibitors in a transgenic mouse model of gallbladder carcinoma. Clin Cancer Res 2005;11(15):5572-5580 